\title{
Benzyl isothiocyanate alters the gene expression with cell cycle regulation and cell death in human brain glioblastoma GBM 8401 cells
}

\author{
NOU-YING TANG ${ }^{1}$, FU-SHIN CHUEH ${ }^{2}$, CHIEN-CHIH YU ${ }^{3}$, CHING-LUNG LIAO ${ }^{1}$, JEN-JYH LIN ${ }^{4}$, \\ TE-CHUN HSIA ${ }^{5}$, KING-CHUEN WU ${ }^{6}$, HSIN-CHUNG LIU ${ }^{7}, \mathrm{KUNG}^{2}$ WEN LU ${ }^{8 *}$ and JING-GUNG CHUNG ${ }^{7,9^{*}}$ \\ ${ }^{1}$ School of Chinese Medicine, China Medical University, Taichung 404; ${ }^{2}$ Department of Health and Nutrition Biotechnology, \\ Asia University, Taichung $413 ;{ }^{3}$ School of Pharmacy, China Medical University, Taichung 404; \\ ${ }^{4}$ Division of Cardiology and ${ }^{5}$ Department of Internal Medicine, China Medical University Hospital, Taichung 404; \\ ${ }^{6}$ Department of Anesthesiology, E-Da Hospital/I-Shou University, Kaohsiung 824, Taiwan; \\ ${ }^{7}$ Department of Biological Science and Technology, and ${ }^{8}$ School of Post-Baccalaureate Chinese Medicine, \\ China Medical University, Taichung 404; ${ }^{9}$ Department of Biotechnology, Asia University, Taichung 413, Taiwan, R.O.C.
}

Received November 3, 2015; Accepted December 12, 2015

DOI: $10.3892 / o r .2016 .4577$

\begin{abstract}
Glioblastoma multiforme (GBM) is a highly malignant devastating brain tumor in adults. Benzyl isothiocyanate (BITC) is one of the isothiocyanates that have been shown to induce human cancer cell apoptosis and cell cycle arrest. Herein, the effect of BITC on cell viability and apoptotic cell death and the genetic levels of human brain glioblastoma GBM 8401 cells in vitro were investigated. We found that BITC induced cell morphological changes, decreased cell viability and the induction of cell apoptosis in GBM 8401 cells was time-dependent. cDNA microarray was used to examine the effects of BITC on GBM 8401 cells and we found that numerous genes associated with cell death and cell cycle regulation in GBM 8401 cells were altered after BITC treatment. The results show that expression of 317 genes was upregulated, and two genes were associated with DNA damage, the DNA-damage-inducible transcript 3 (DDIT3) was increased 3.66-fold and the growth arrest and DNA-damage-inducible $\alpha$ (GADD45A) was increased 2.34-fold. We also found that expression of 182 genes was
\end{abstract}

Correspondence to: Professor Jing-Gung Chung, Department of Biological Science and Technology, China Medical University, 91 Hsueh-Shih Road, Taichung 404, Taiwan, R.O.C.

E-mail: jgchung@mail.cmu.edu.tw

Professor Kung-Wen Lu, School of Post-Baccalaureate Chinese Medicine, China Medical University, 91 Hsueh-Shih Road, Taichung 404, Taiwan, R.O.C.

E-mail:kwlu@mail.cmu.edu.tw

*Contributed equally

Key words: benzyl isothiocyanate, gene, cell cycle arrest, regulation, glioblastoma downregulated and two genes were associated with receptor for cell responses to stimuli, the EGF containing fibulin-like extracellular matrix protein 1 (EFEMP1) was inhibited 2.01fold and the TNF receptor-associated protein 1 (TRAP1) was inhibited 2.08-fold. BITC inhibited seven mitochondria ribosomal genes, the mitochondrial ribosomal protein; tumor protein D52 (MRPS28) was inhibited 2.06-fold, the mitochondria ribosomal protein S2 (MRPS2) decreased 2.07-fold, the mitochondria ribosomal protein L23 (MRPL23) decreased 2.08-fold, the mitochondria ribosomal protein S2 (MRPS2) decreased 2.07-fold, the mitochondria ribosomal protein $\mathrm{S} 12$ (MRPS12) decreased 2.08-fold, the mitochondria ribosomal protein L12 (MRPL12) decreased 2.25-fold and the mitochondria ribosomal protein S34 (MRPS34) was decreased 2.30-fold in GBM 8401 cells. These changes of gene expression can provide the effects of BITC on the genetic level and are potential biomarkers for glioblastoma therapy.

\section{Introduction}

Glioblastomas are the most frequent and aggressive primary brain cancers in adults (1) with a high recurrence and mortality rate (2). Glioblastoma prognosis is poor and there are limited therapeutic options. In recent years, advances have been made in multimodality including surgery, radiotherapy, chemotherapy and biotherapy, but the overall 5-year survival rate is still $<3 \%$ for patients with glioblastoma (3). Thus, we try to identify prognostic gene expression (upregulation or downregulation) that may contribute to evaluate a more effective treatment to improve patient survival and to address more precisely the use of comprehensive therapy.

Benzyl isothiocyanate (BITC), one of the isothiocyanates, is present in cruciferous plants, it acts against carcinogenesis $(4,5)$ and induces cell death through the induction of apoptosis and cell cycle arrest in various human cancer cells (6-10). In human prostate cancer cells, BITC promoted the phosphorylation of Bcl-xL with simultaneous 
cell cycle arrest and subsequent apoptosis (11). In our previous studies we have demonstrated that BITC inhibited migration and invasion in human colon (12) and gastric (13) cancer cells in vitro. There is no available information to show whether BITC affects human brain tumor cells, in particular regarding the effects of BITC on gene expression in human glioblastoma cells.

In cell survival, to maintain the integrity of genomic and mitochondrial DNA is critically important. It was reported that damage to nuclear and mitochondrial DNA can increase the accumulation of defective cellular components leading to impact unfavorably on physiological functions, increasing entropy (14). If an agent induces DNA damage, the cell in order to respond to the DNA damage, activates the cell cycle checkpoints (G1, S and G2/M) to stop cell cycle progression in order to allow time for repair, thereby preventing transmission of damaged or incompletely replicated chromosomes (15). Thus, the associated gene expression regarding cell cycle progression, cell apoptosis and DNA damage in cells are important for cancer cell therapy. There is no previous study showing the anticancer properties of BITC at the genetic level of human glioblastoma. We investigated the effects of BITC on gene expression in human brain cancer glioblastoma multiforme (GBM 8401) in vitro.

\section{Materials and methods}

Chemicals and reagents. BITC, dimethyl sulfoxide (DMSO), penicillin-streptomycin and trypsin-EDTA were obtained from Sigma Chemical Co. (St. Louis, MO, USA). RPMI-1640 culture medium and fetal bovine serum (FBS) were purchased from Gibco-BRL/Invitrogen (Carlsbad, CA, USA). Tissue culture flasks and plates were obtained from Gibco-BRL/Invitrogen.

Cell culture. Human brain glioblastoma GBM 8401 cells were purchased from the Food Industry Research and Development Institute (Hsinchu, Taiwan) and cultured following the supplier's instructions. Cells were grown in $75 \mathrm{~cm}^{2}$ culture flasks with RPMI-1640 medium supplemented with 10\% FBS, $100 \mathrm{U} / \mathrm{ml}$ penicillin and $100 \mu \mathrm{g} / \mathrm{ml}$ streptomycin and maintained in an atmosphere of $5 \% \mathrm{CO}_{2}$ and $95 \%$ air at $37^{\circ} \mathrm{C}$. The medium was changed every 2 days (16).

Cell morphological changes and viability assays. GBM 8401 cells $\left(8 \times 10^{4}\right.$ cells $\left./ \mathrm{ml}\right)$ were seeded into a 12 -well plate containing RPMI-1640 medium for $24 \mathrm{~h}$. In addition, BITC was added to wells at the final concentration of $6 \mu \mathrm{M}$ for 0,12 , 24 and $48 \mathrm{~h}$. After treatment, cells were examined and photographed using contrast-phase microscopy at a magnification of $\mathrm{x} 400$ and then harvested for measuring the total percentage of viable cells using flow cytometric assay (16).

Annexin V/PI staining for cell apoptosis. GBM 8401 cells $\left(8 \times 10^{4}\right.$ cells $\left./ \mathrm{ml}\right)$ were seeded into a 12 -well plate for $24 \mathrm{~h}$ and then treated with BITC (0 and $6 \mu \mathrm{M})$ for $0,12,24$ and $48 \mathrm{~h}$, and the cells were collected, washed with phosphate-buffered saline (PBS) and stained with Annexin V/propidium iodide (PI) staining kit (BD Biosciences, San Diego, CA, USA) (17). All samples were then immediately analyzed by flow cytometry.
cDNA microarray assay for gene expression. GBM 8401 cells $\left(2.4 \times 10^{6}\right.$ cells/dish) were maintained in a $10 \mathrm{~cm}$ dish for $24 \mathrm{~h}$. Cells were treated with $6 \mu \mathrm{M}$ BITC or DMSO for $48 \mathrm{~h}$ then cells were collected, and washed twice with PBS. All samples were further isolated in total RNA using Qiagen RNeasy Mini kit (Qiagen, Valencia, CA, USA). The isolated RNA was further conducted for cDNA synthesis, labeling and microarray hybridization. The fluorescent-labeled cDNA hybridization (Affymetrix GeneChip Human Gene 1.0 ST array; Affymetrix, Santa Clara, CA, USA) on the chip was conducted (18), and the fluorescence from each sample was measured by Asia BioInnovations Corporation (Taipei, Taiwan). Expression Console software (Affymetrix) with default RNA parameters $(19,20)$ was used to analyze the data. BITC affecting gene expression with at least a 2-fold-change was considered significant and recorded.

\section{Results}

Cytotoxic effects of BITC in GBM 8401 cells. To investigate the cytotoxic effects of BITC in GBM 8401 cells, after treatment of cells with $6 \mu \mathrm{M}$ BITC for $0,12,24$ and $48 \mathrm{~h}$, the cell morphological changes and percentage of viable cells were measured and results are presented in Fig. 1A and B, respectively. BITC induced cell morphological changes and decreased cell viability in GBM 8401 cells and these effects are time-dependent (Fig. 1A and B).

Induction of cell apoptosis in GBM 8401 cells after exposure to BITC. In order to further examine whether cell death was induced by BITC and through the induction of cell apoptosis, the cells after treatment with $6 \mu \mathrm{M}$ BITC were harvested and apoptotic cells were measured by Annexin V/PI staining, and the results are presented in Fig. 2. Based on the data in Fig. 2, BITC-induced apoptotic cell death and these effects are time-dependent. The treatment of cells with BITC increased the total apoptotic cell death to $36.81 \%$ at $48 \mathrm{~h}$ (Table I). The result is consistent with the morphology and examination of total viable cells.

BITC alters the regulations of gene expression in GBM 8401 cells. GBM 8401 cells were treated with or without $6 \mu \mathrm{M}$ BITC for $48 \mathrm{~h}$ and then harvested for total RNA extraction. The expression of the top 10 up- and downregulated genes was estimated by cDNA microarray analysis and the results are presented in Tables II and III. BITC induced 317 upregulated genes and 182 downregulated genes of GBM 8401, respectively. Fourty-six genes were upregulated in the range $>3-<4$-fold, and 198 genes were upregulated $>2-<3$-fold. One gene was downregulated $>4$-fold, and 11 genes were downregulated in the range $>3-<4$-fold, and 170 genes were downregulated $>2-<3$-fold (data not shown).

Alterations in gene expression scored in GBM 8401 cells after exposure to BITC. The data from GeneGo analysis were mapped and are shown as upward thermometers in red color and indicate upregulated signals and downward (blue) ones indicate downregulated expression levels of the genes as presented in Figs. 3-5. Fig. 3 shows the Development_ Hedgehog and PTH signaling pathways in bone and 
A

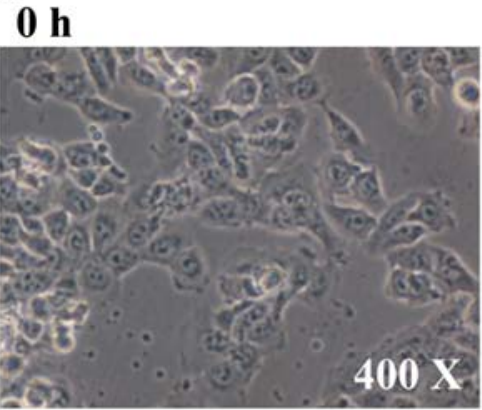

\section{$24 \mathrm{~h}$}

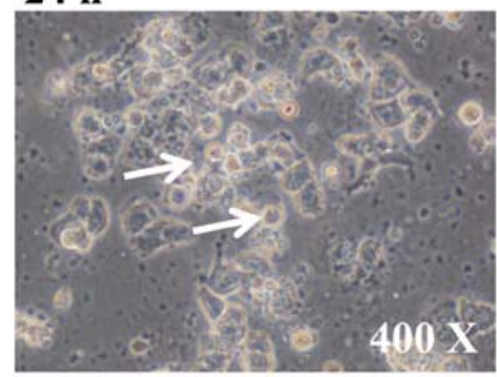

$12 \mathrm{~h}$

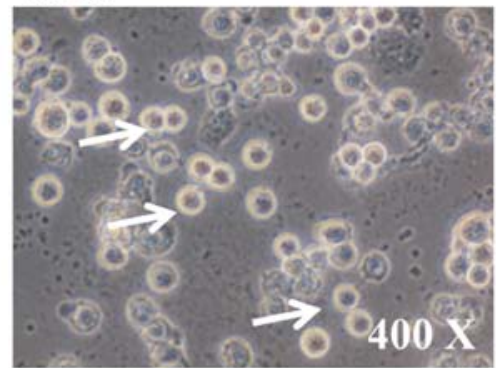

$48 \mathrm{~h}$

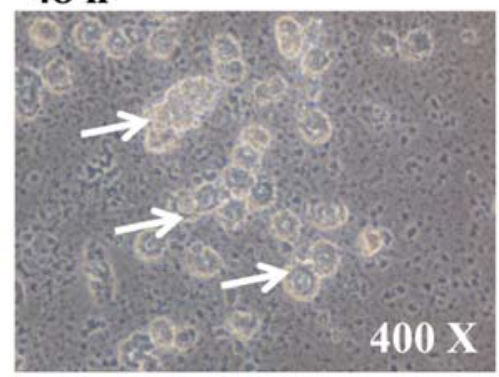



Table I. BITC-induced apoptosis of GBM 8401 cells.

\begin{tabular}{cccc}
\hline Hours & $\begin{array}{c}\text { Viable } \\
\text { cells }(\%)\end{array}$ & $\begin{array}{c}\text { Early apoptotic } \\
\text { cells }(\%)\end{array}$ & $\begin{array}{c}\text { Late apoptotic } \\
\text { cells }(\%)\end{array}$ \\
\hline 0 & $95.69 \pm 1.24$ & $1.87 \pm 0.47$ & $2.33 \pm 0.77$ \\
12 & $70.34 \pm 1.04^{\mathrm{b}}$ & $11.48 \pm 1.90^{\mathrm{b}}$ & $15.51 \pm 3.91^{\mathrm{b}}$ \\
24 & $66.15 \pm 3.44^{\mathrm{b}}$ & $24.62 \pm 1.80^{\mathrm{b}}$ & $7.87 \pm 1.41^{\mathrm{a}}$ \\
48 & $59.35 \pm 2.80^{\mathrm{b}}$ & $28.88 \pm 1.32^{\mathrm{b}}$ & $7.93 \pm 0.67^{\mathrm{a}}$ \\
\hline
\end{tabular}

Cells were treated with $6 \mu \mathrm{M}$ of BITC for $0,12,24$ and $48 \mathrm{~h}$ before the cells were stained using Annexin V/PI staining and analyzed by flow cytometry as described in Materials and methods. Data were obtained from three independent experiments. ${ }^{\mathrm{a}} \mathrm{p}<0.05,{ }^{\mathrm{b}} \mathrm{p}<0.001$ significant difference between BITC-treated groups and the control as analyzed by Student's t-test.

cartilage development. Fig. 4 shows the transcription and epigenetic regulation of gene expression and Fig. 5 shows the Development_TGF- $\beta$-dependent induction of EMT via MAPK.

\section{Discussion}

Numerous studies have shown that BITC present biological activities including anticancer function in vitro. In the present study, BITC-induced cell morphological changes (Fig. 1A) and decreased the percentage of viable GBM 8401 cells and these effects are time-dependent (Fig. 1B). We also used Annexin V/PI staining to show that BITC-induced cell death through the induction of cell apoptosis in GBM 8401 cells (Fig. 2 and Table I) these effects are time-dependent. In order to further examine whether or not BITC affects gene expression of GBM 8401 cells, we treated cells with $6 \mu \mathrm{M}$ of BITC for $24 \mathrm{~h}$ before cells were harvested, total RNA was extracted for cDNA microarray and underwent further analysis for gene expression and the results are shown in Tables II and III.

It is well documented that after cells are exposed to anticancer agents, it may cause DNA damage or induce cell cycle arrest for causing cell death (21-23). We found that BITC decreased total viable cell number (Fig. 1B) based on cells incubated with BITC and then harvesting and staining by PI and examination by flow cytometric assay as previ- 

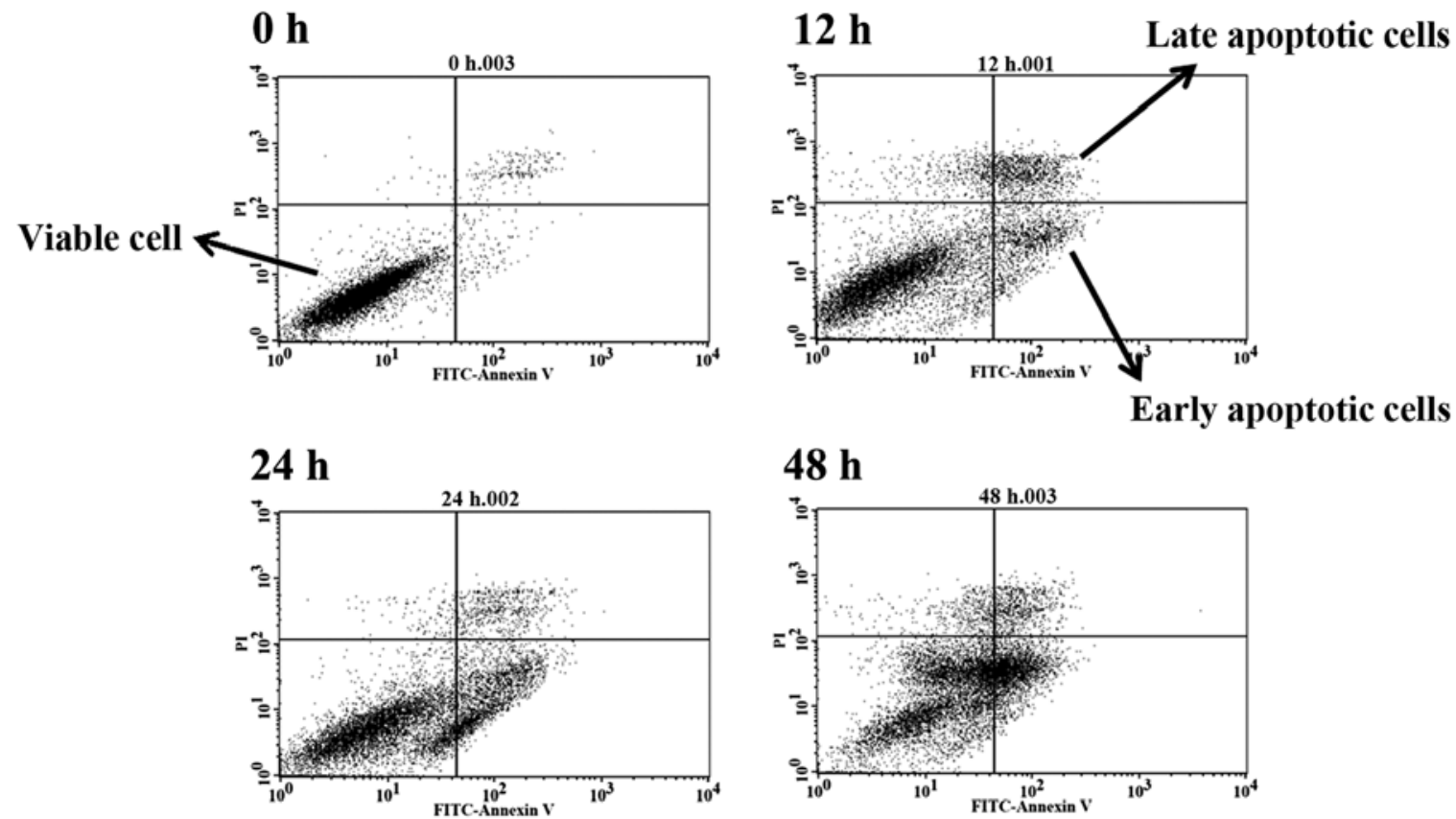

Figure 2. BITC induces apoptosis of GBM 8401 cells. Cells were treated with $6 \mu \mathrm{M}$ of BITC for $0,12,24$ and $48 \mathrm{~h}$ before the cells were stained using Annexin V/PI staining and were analyzed by flow cytometry as described in Materials and methods. Data profiles of flow cytometric assay.

Table II. The top 10 upregulated genes of GBM 8401 cells by BITC treatment.

\begin{tabular}{lll}
\hline Fold-change & Gene symbol & \\
\hline 11.04 & LPAR6 & Lysophosphatidic acid receptor 6 \\
9.11 & LOC344887 & NmrA-like family domain containing 1 pseudogene \\
8.26 & EGR1 & Early growth response 1 \\
7.65 & CLU & Custerin \\
7.56 & CTH & Cystathionase (cystathionine $\gamma$-lyase) \\
6.05 & SAT1 & Spermidine/spermine N1-acetyltransferase 1 \\
5.81 & SLC7A11 & Solute carrier family 7 (anionic amino acid transporter light chain, xc-system), member 11 \\
5.09 & AKR1B10 & Aldo-keto reductase family 1, member B10 (aldose reductase) \\
4.90 & HIST2H4B & Histone cluster 2, H4b; H4a; histone cluster 4, H4; \\
& & histone cluster 1, H4l; H4e; H4b; H4h; H4c; \\
4.62 & SLCO1B7 & S4j; H4k; H4f; H4d; H4a; H4i \\
\hline
\end{tabular}

BITC, benzyl isothiocyanate.

ously described (24,25). We also confirmed cell apoptosis by Annexin V/PI staining and evaluation by flow cytometry and results indicated that BITC significantly induced cell death in GBM 8401 cells in vitro (Fig. 2).

Table II indicates that expression of 317 genes was promoted, and among them two genes associated with DNA damage in GBM 8401 cells, the DNA-damage-inducible transcript 3 (DDIT3) was increased 3.66-fold, and the growth arrest and DNA-damage-inducible $\alpha$ (GADD45A) was increased 2.34-fold. Based on these observations, BITC induced DNA damage as shown previously (9), our results indicated that BITC-induced DNA damage was associated with gene expression. Table II indicates that BITC also promoted four heat protein gene expression, the heat shock protein $70 \mathrm{kDa}$ family member 13 (HSPA13), which was increased 2.16-fold, the heat shock protein $70 \mathrm{kDa}$ protein 1A, 1B (HSPA1A) increased 2.13-fold [heat shock protein $90 \mathrm{kDa} \beta$ (Grp94), membrane 2, pseudogene (HSP90B2P)] and increased 2.03-fold. It was reported that heat shock proteins (HSPs) have anti-apoptotic properties and they are often elevated in many human cancers; furthermore, the overexpression of HSPs is associated with poor survival and response to therapy (26-28). HSP expression in selected brain tumor cell lines $(27,29)$ have been reported using 
Table III. The top 10 genes of GBM 8401 cells downregulated by BITC treatment.

\begin{tabular}{lll}
\hline Fold-change & Gene symbol & \multicolumn{1}{c}{ mRNA description } \\
\hline-3.11 & LOC730755 & Keratin associated protein 2-4-like; 2-1; 2-4 \\
-3.12 & DKC1 & Dyskeratosis congenita 1, dyskerin; small nucleolar RNA, H/ACA box 56 \\
-3.18 & HIST1H1D & Histone cluster 1, H1d \\
-3.24 & $A C T C 1$ & Actin, $\alpha$, cardiac muscle 1 \\
-3.28 & $E D N 1$ & Endothelin 1 \\
-3.71 & HIST1H2AB & Histone cluster 1, H2ab; histone cluster 1, H2ae \\
-3.74 & HIST1H2BI & Histone cluster 1, H2bi; H2bc; H2be; H2bf; H2bg \\
-3.76 & TRNAU2 & Transfer RNA selenocysteine 2 (anticodon UCA) \\
-3.77 & KRT81 & Keratin 81 \\
-4.43 & VTRNA1-1 & Vault RNA 1-1 \\
\hline
\end{tabular}

BITC, benzyl isothiocyanate.

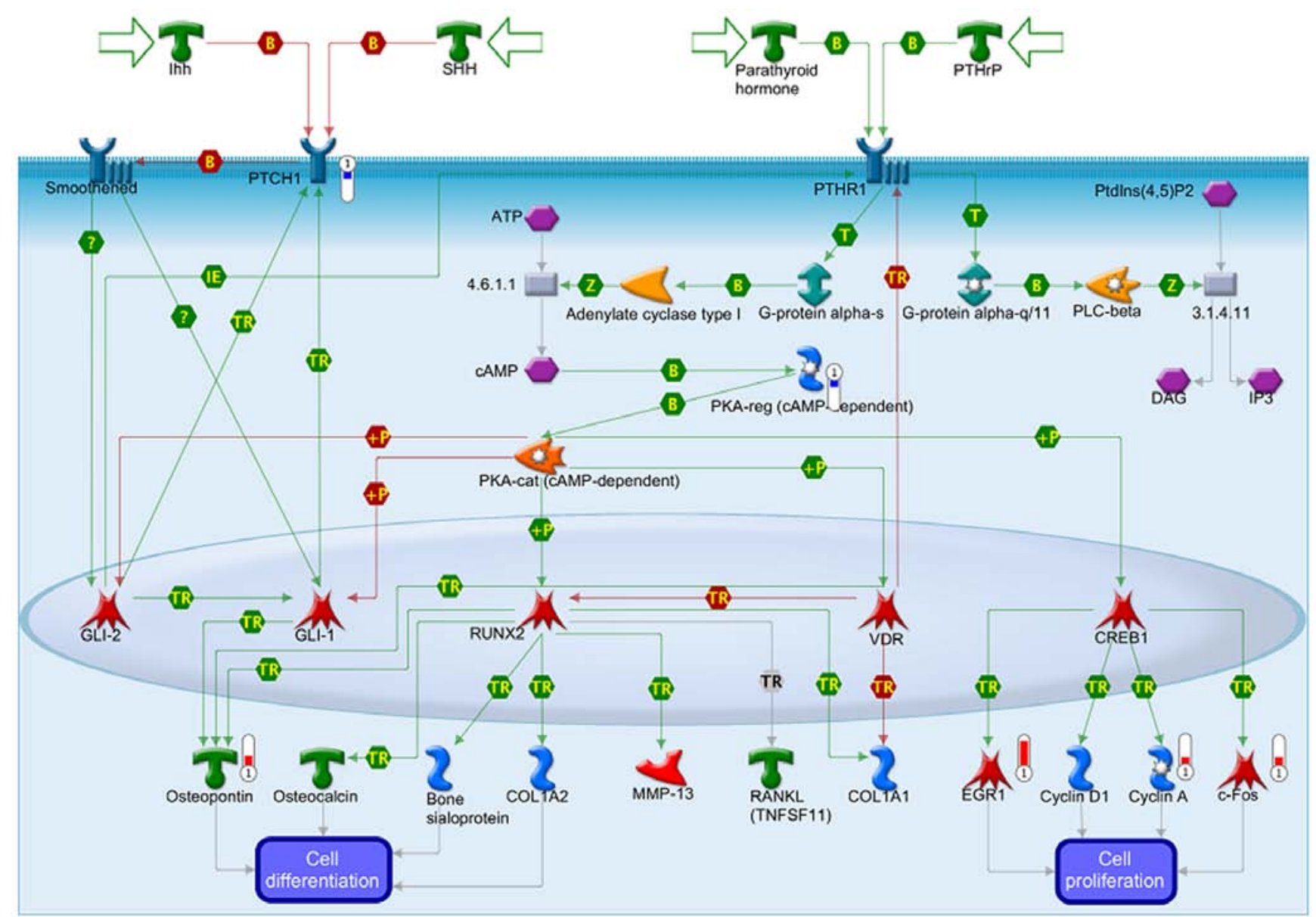

Figure 3. Development_Hedgehog and PTH signaling pathways in bone and cartilage development. The top scored map (map with the lowest p-value) based on the enrichment distribution sorted by 'Statistically significant Maps' set. Experimental data from all files is linked to and visualized on the maps as thermometer-like figures. Upward thermometers have red color and indicate upregulated signals and downward (blue) ones indicate downregulated expression levels of the genes.

mainly immunohistochemistry (29-31). Table II indicates that BITC also promoted expression of seven genes associated with cell cycle such as CLK (CDC-like kinase 4), which was increased 3.29-fold, CCNG2 (cyclin G2) was increased 3.19- fold, cyclin A1 (CCNA1) increased 2.30-fold, cyclin Y-like 1 (CCNYL1) increased 2.20-fold, cyclin-dependent kinase-like 5 (CDKL5) increased 2.19-fold, cyclin D binding myb-like transcription factor 1 (DMTF1) increased 2.04-fold and 


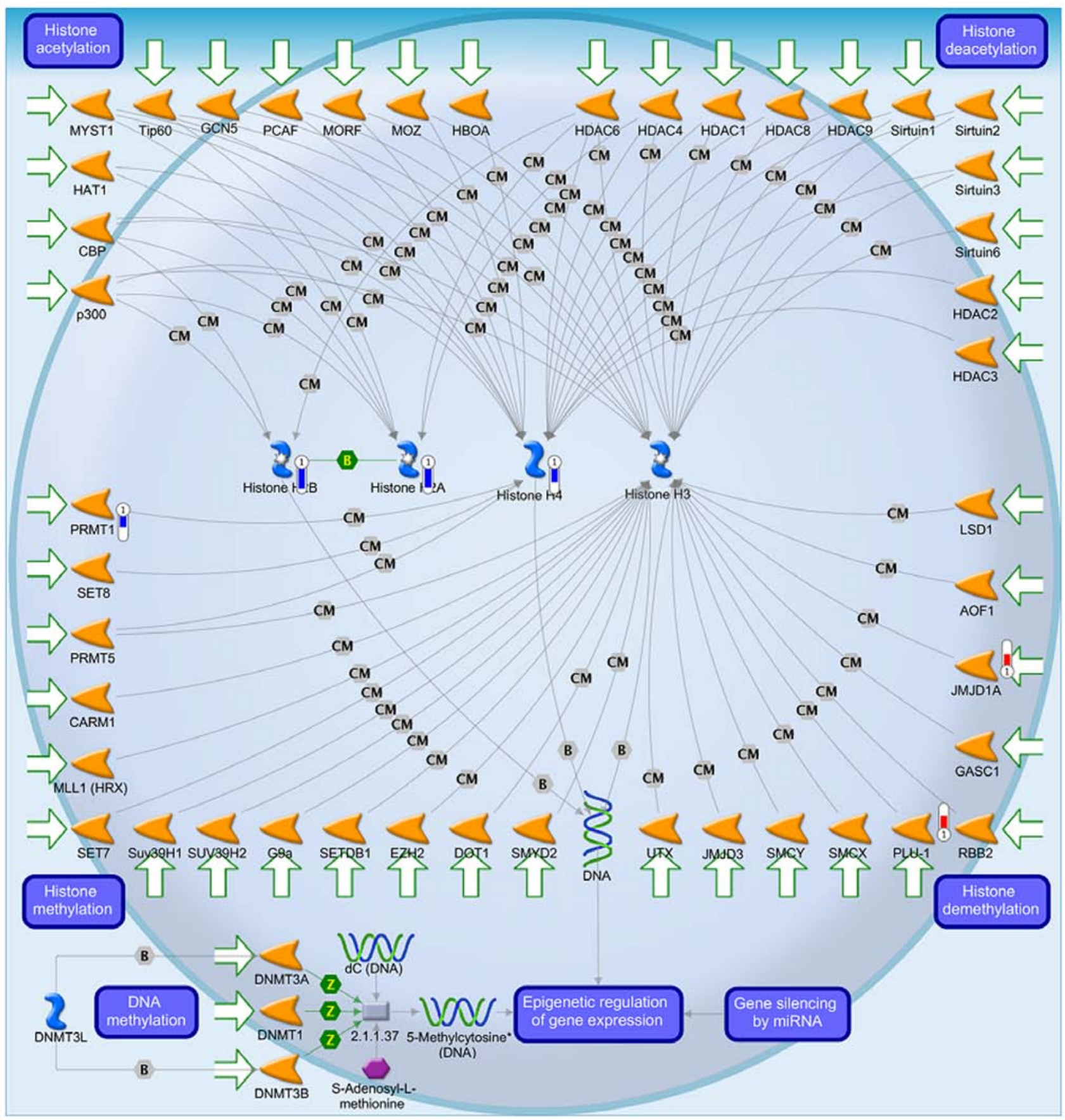

Figure 4. Transcription and epigenetic regulation of gene expression. The second scored map (map with the second lowest p-value) based on the enrichment distribution sorted by 'Statistically significant Maps' set. Experimental data from all files is linked to and visualized on the maps as thermometer-like figures. Upward thermometers have red color and indicate upregulated signals and downward (blue) ones indicate downregulated expression levels of the genes.

cell cycle progression 1 (CCPG1) was increased 2.01-fold in GBM 8401 cells.

Table III indicates that it suppressed expression of 182 genes in GBM 8401 cells, and among them a gene associated with receptor for cell responses to stimuli, the EGF containing fibulin-like extracellular matrix protein 1 (EFEMP1) was inhibited 2.01-fold, and the TNF receptor-associated protein 1 (TRAP1) was inhibited 2.08-fold. Both receptors are associated with cell sensitivity for stimuli agents $(32,33)$. Furthermore, BITC inhibited mitochondria ribosomal genes such as mitochondrial ribosomal protein; tumor protein D52
(MRPS28) was inhibited 2.06-fold, mitochondria ribosomal protein S2 (MRPS2) decreased 2.07-fold, mitochondria ribosomal protein L23 (MRPL23) decreased 2.08-fold, mitochondria ribosomal protein S2 (MRPS2) decreased 2.07-fold, mitochondria ribosomal protein S12 (MRPS12) decreased 2.08-fold, mitochondria ribosomal protein L12 (MRPL12) decreased 2.25-fold and mitochondria ribosomal protein S34 (MRPS34) was decreased 2.30-fold in GBM 8401 cells. It is well documented that agents inducing cancer cell apoptosis are involved in the mitochondria $(34,35)$, thus, in the present study, we found that BITC-induced cell death may be through 


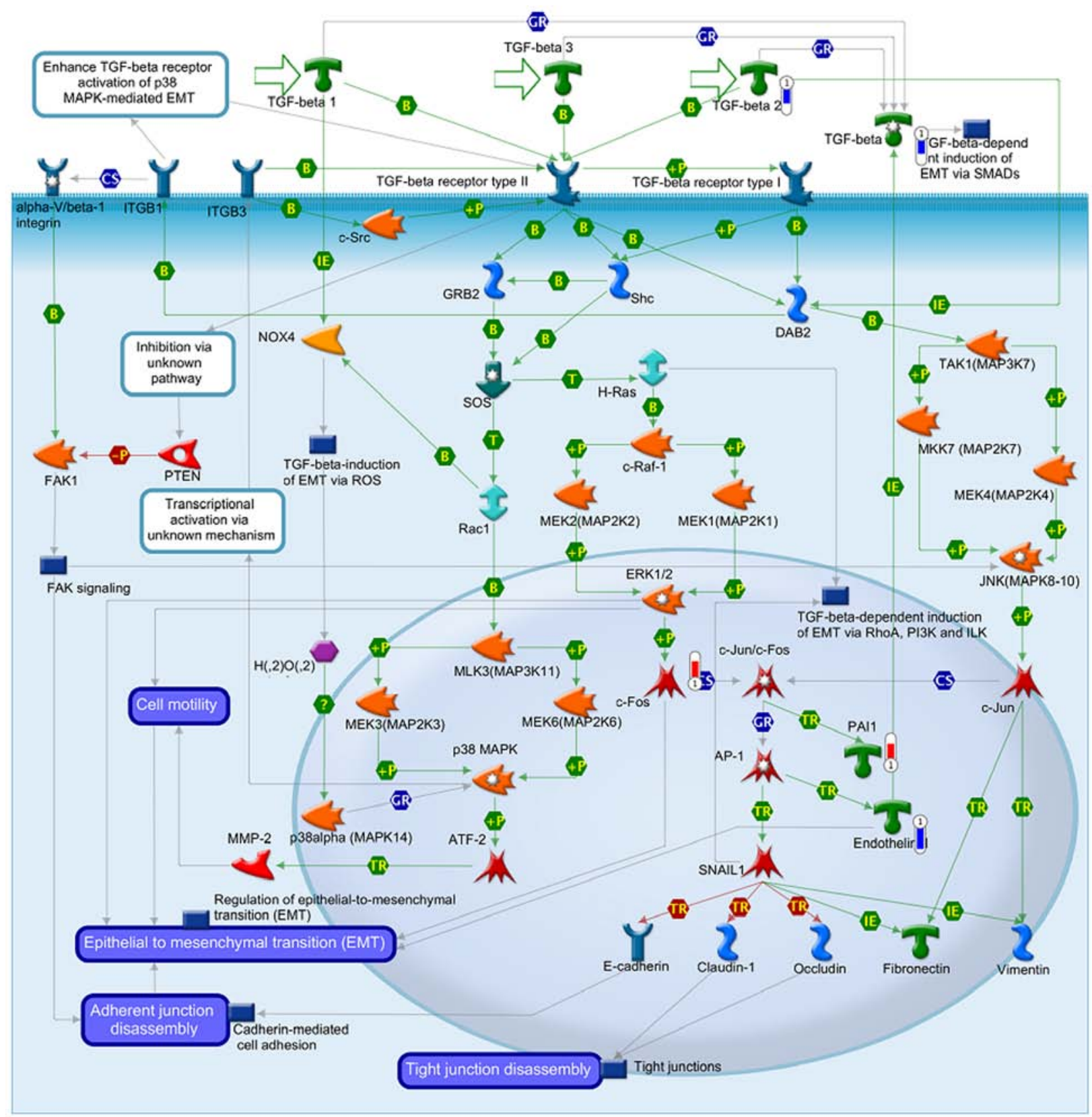

Figure 5. Development_TGF- $\beta$-dependent induction of EMT via MAPK. The third scored map (map with the third lowest p-value) based on the enrichment distribution sorted by 'Statistically significant Maps' set. Experimental data from all files is linked to and visualized on the maps as thermometer-like figures. Upward thermometers have red color and indicate upregulated signals and downward (blue) ones indicate downregulated expression levels of the genes.

the induction of DNA damage and affects mitochondria ribosomal gene expression in GBM 8401 cells.

In conclusion, we found that many genes are associated with DNA damage and cell cycle regulation and various genes that associated with the mitochondria were affected by BITC in GBM 8401 cells. These changes of gene expression in GBM 8401 cells, after exposure to BITC, provide further knowledge on the effects of BITC at the genetic level, and for future development of potential biomarkers for glioblastoma therapy.

\section{Acknowledgements}

The present study was supported by grant no.CMU103-ASIA-01 from the China Medical University, Taichung, Taiwan.

\section{References}

1. Di Cristofori A, Ferrero S, Bertolini I, Gaudioso G, Russo MV, Berno V, Vanini M, Locatelli M, Zavanone M, Rampini P, et al: The vacuolar $\mathrm{H}^{+}$ATPase is a novel therapeutic target for glioblastoma. Oncotarget 6: 17514-17531, 2015.

2. Wen PY and Kesari S: Malignant gliomas in adults. N Engl J Med 359: 492-507, 2008.

3. Stupp R, Mason WP, van den Bent MJ, Weller M, Fisher B, Taphoorn MJ, Belanger K, Brandes AA, Marosi C, Bogdahn U, et al; European Organisation for Research and Treatment of Cancer Brain Tumor and Radiotherapy Groups; National Cancer Institute of Canada Clinical Trials Group: Radiotherapy plus concomitant and adjuvant temozolomide for glioblastoma. $\mathrm{N}$ Engl J Med 352: 987-996, 2005.

4. Nakamura Y and Miyoshi N: Cell death induction by isothiocyanates and their underlying molecular mechanisms. Biofactors 26: 123-134, 2006. 
5. Sehrawat A and Singh SV: Benzyl isothiocyanate inhibits epithelial-mesenchymal transition in cultured and xenografted human breast cancer cells. Cancer Prev Res 4: 1107-1117, 2011.

6. Huang SH, Wu LW, Huang AC, Yu CC, Lien JC, Huang YP, Yang JS, Yang JH, Hsiao YP, Wood WG, et al: Benzyl isothiocyanate (BITC) induces $\mathrm{G} 2 / \mathrm{M}$ phase arrest and apoptosis in human melanoma A375.S2 cells through reactive oxygen species (ROS) and both mitochondria-dependent and death receptor-mediated multiple signaling pathways. J Agric Food Chem 60: 665-675, 2012.

7. Singh SV, Srivastava SK, Choi S, Lew KL, Antosiewicz J, Xiao D, Zeng Y, Watkins SC, Johnson CS, Trump DL, et al: Sulforaphane-induced cell death in human prostate cancer cells is initiated by reactive oxygen species. J Biol Chem 280: 19911-19924, 2005.

8. Wicker CA, Sahu RP, Kulkarni-Datar K, Srivastava SK and Brown TL: BITC sensitizes pancreatic adenocarcinomas to TRAIL-induced apoptosis. Cancer Growth Metastasis 2009: 45-55, 2010.

9. Wu CL, Huang AC, Yang JS, Liao CL, Lu HF, Chou ST, Ma CY, Hsia TC, Ko YC and Chung JG: Benzyl isothiocyanate (BITC) and phenethyl isothiocyanate (PEITC)-mediated generation of reactive oxygen species causes cell cycle arrest and induces apoptosis via activation of caspase-3, mitochondria dysfunction and nitric oxide (NO) in human osteogenic sarcoma U-2 OS cells. J Orthop Res 29: 1199-1209, 2011.

10. Xiao D, Powolny AA and Singh SV: Benzyl isothiocyanate targets mitochondrial respiratory chain to trigger reactive oxygen species-dependent apoptosis in human breast cancer cells. J Biol Chem 283: 30151-30163, 2008.

11. Basu A and Haldar S: Dietary isothiocyanate mediated apoptosis of human cancer cells is associated with $\mathrm{Bcl}-\mathrm{xL}$ phosphorylation. Int J Oncol 33: 657-663, 2008

12. Lai KC, Huang AC, Hsu SC, Kuo CL, Yang JS, Wu SH and Chung JG: Benzyl isothiocyanate (BITC) inhibits migration and invasion of human colon cancer HT29 cells by inhibiting matrix metalloproteinase-2/-9 and urokinase plasminogen (uPA) through PKC and MAPK signaling pathway. J Agric Food Chem 58: 2935-2942, 2010

13. Ho CC, Lai KC, Hsu SC, Kuo CL, Ma CY, Lin ML, Yang JS and Chung JG: Benzyl isothiocyanate (BITC) inhibits migration and invasion of human gastric cancer AGS cells via suppressing ERK signal pathways. Hum Exp Toxicol 30: 296-306, 2011.

14. Salminen A and Kaarniranta K: Genetics vs. entropy: Longevity factors suppress the NF-kappaB-driven entropic aging process Ageing Res Rev 9: 298-314, 2010.

15. Erol A: Genotoxic stress-mediated cell cycle activities for the decision of cellular fate. Cell Cycle 10: 3239-3248, 2011.

16. Wang DY, Yeh CC, Lee JH, Hung CF and Chung JG: Berberine inhibited arylamine $\mathrm{N}$-acetyltransferase activity and gene expression and DNA adduct formation in human malignant astrocytoma (G9T/VGH) and brain glioblastoma multiforms (GBM 8401) cells. Neurochem Res 27: 883-889, 2002.

17. Kwon HY, Kim KS, An HK, Moon HI, Kim HJ and Lee YC: Triptolide induces apoptosis through extrinsic and intrinsic pathways in human osteosarcoma U2OS cells. Indian J Biochem Biophys 50: 485-491, 2013

18. Hsia TC, Yu CC, Hsu SC, Tang NY, Lu HF, Yu CS, Wu SH, Lin JG and Chung JG: cDNA microarray analysis of the effect of cantharidin on DNA damage, cell cycle and apoptosis-associated gene expression in NCI-H460 human lung cancer cells in vitro. Mol Med Rep 12: 1030-1042, 2015.

19. Gardina PJ, Clark TA, Shimada B, Staples MK, Yang Q, Veitch J, Schweitzer A, Awad T, Sugnet C, Dee S, et al: Alternative splicing and differential gene expression in colon cancer detected by a whole genome exon array. BMC Genomics 7: 325, 2006
20. Lin JJ, Yu CC, Lu KW, Chang SJ, Yu FS, Liao CL, Lin JG and Chung JG: $\alpha$-Phellandrene alters expression of genes associated with DNA damage, cell cycle, and apoptosis in murine leukemia WEHI-3 cells. Anticancer Res 34: 4161-4180, 2014.

21. Li X, Tian J, Bo Q, Li K, Wang H, Liu T and Li J: Targeting DNA-PKcs increased anticancer drug sensitivity by suppressing DNA damage repair in osteosarcoma cell line MG63. Tumour Biol 36: 9365-9372, 2015.

22. Neumann J, Yang Y, Köhler R, Giaisi M, Witzens-Harig M, Liu D, Krammer PH, Lin W and Li-Weber M: Mangrove dolabrane-type of diterpenes tagalsins suppresses tumor growth via ROS-mediated apoptosis and ATM/ATR-Chk1/Chk2regulated cell cycle arrest. Int J Cancer 137: 2739-2748, 2015.

23. Zhang D, Tang B, Xie X, Xiao YF, Yang SM and Zhang JW: The interplay between DNA repair and autophagy in cancer therapy. Cancer Biol Ther 16: 1005-1013, 2015.

24. Anuchapreeda S, Tima S, Duangrat C and Limtrakul P: Effect of pure curcumin, demethoxycurcumin, and bisdemethoxycurcumin on WT1 gene expression in leukemic cell lines. Cancer Chemother Pharmacol 62: 585-594, 2008.

25. Ji BC, Hsu WH, Yang JS, Hsia TC, Lu CC, Chiang JH, Yang JL, Lin CH, Lin JJ, Suen LJ, et al: Gallic acid induces apoptosis via caspase-3 and mitochondrion-dependent pathways in vitro and suppresses lung xenograft tumor growth in vivo. J Agric Food Chem 57: 7596-7604, 2009.

26. Ciocca DR and Calderwood SK: Heat shock proteins in cancer: Diagnostic, prognostic, predictive, and treatment implications. Cell Stress Chaperones 10: 86-103, 2005.

27. Ciocca DR, Rozados VR, Cuello Carrión FD, Gervasoni SI, Matar P and Scharovsky OG: Hsp25 and Hsp70 in rodent tumors treated with doxorubicin and lovastatin. Cell Stress Chaperones 8: 26-36, 2003.

28. Gyrd-Hansen M, Nylandsted J and Jäättelä M: Heat shock protein 70 promotes cancer cell viability by safeguarding lysosomal integrity. Cell Cycle 3: 1484-1485, 2004.

29. Graner MW and Bigner DD: Chaperone proteins and brain tumors: Potential targets and possible therapeutics. Neuro Oncol 7: 260-278, 2005.

30. Alexiou GA, Vartholomatos G, Stefanaki K, Patereli A, Dova L, Karamoutsios A, Lallas G, Sfakianos G, Moschovi M and Prodromou N: Expression of heat shock proteins in medulloblastoma. J Neurosurg Pediatr 12: 452-457, 2013.

31. AssimakopoulouM:Humanmeningiomas:Immunohistochemical localization of progesterone receptor and heat shock protein 27 and absence of estrogen receptor and PS2. Cancer Detect Prev 24: $163-168,2000$

32. Kim YJ, Yoon HY, Kim SK, Kim YW, Kim EJ, Kim IY and Kim WJ: EFEMP1 as a novel DNA methylation marker for prostate cancer: Array-based DNA methylation and expression profiling. Clin Cancer Res 17: 4523-4530, 2011.

33. Ou Y, Liu L, Xue L, Zhou W, Zhao Z, Xu B, Song Y and Zhan Q: TRAP1 shows clinical significance and promotes cellular migration and invasion through STAT3/MMP2 pathway in human esophageal squamous cell cancer. J Genet Genomics 41: 529-537, 2014.

34. Ly JD, Grubb DR and Lawen A: The mitochondrial membrane potential $(\Delta \psi \mathrm{m})$ in apoptosis; An update. Apoptosis 8: 115-128, 2003.

35. Rego AC and Oliveira CR: Mitochondrial dysfunction and reactive oxygen species in excitotoxicity and apoptosis: Implications for the pathogenesis of neurodegenerative diseases. Neurochem Res 28: 1563-1574, 2003. 